Preliminary draft 9/19/2013

All rights reserved

\title{
Automatically Green: \\ Behavioral Economics and Environmental Protection
}

\author{
Cass R. Sunstein ${ }^{*}$ and Lucia A. Reisch ${ }^{* *}$
}

\begin{abstract}
Careful attention to choice architecture promises to open up new possibilities for environmental protection - possibilities that go well beyond, and that may be more effective than, the standard tools of economic incentives, mandates, and bans. How, for example, do consumers choose between environmentally-friendly products or services and alternatives that are potentially damaging to the environment but less expensive? The answer may well depend on the default rule. Indeed, green default rules may well be a more effective tool for altering outcomes than large economic incentives. The underlying reasons include the power of suggestion; inertia and procrastination; and loss aversion. If well-chosen, green defaults are likely to have large effects in reducing the economic and environmental harms associated with various products and activities. Such defaults may or may not be more expensive to consumers. In deciding whether to establish green defaults, choice architects should consider both consumer welfare and a wide range of other costs and benefits. Sometimes that assessment will argue strongly in favor of green defaults, particularly when both economic and environmental considerations point in their direction. But when choice architects lack relevant information, when interest-group maneuvering is a potential problem, and when externalities are not likely to be significant, active choosing, perhaps accompanied by various influences (including provision of relevant information), will usually be preferable to a green default.
\end{abstract}

\section{Beyond Incentives}

Suppose that in a relevant community, there are two sources of energy, denominated "green" and "gray." Suppose that consistent with its name, "green" is better than gray on environmental grounds. Those who use green energy emit lower levels of greenhouse gases and also of conventional pollutants. Suppose that those who use gray energy save money. Which will consumers choose?

The obvious response is that the answer will depend on the magnitude of the relevant differences. Suppose that green energy is far better than gray on environmental grounds

\footnotetext{
${ }^{*}$ Robert Walmsley University Professor, Harvard University and Harvard Law School.

${ }^{* *}$ Professor, Copenhagen Business School, Department of Intercultural Communication and Management. We are grateful to Cassie Chambers and Daniel Kanter for excellent research assistance.
} 
and that gray energy costs only very slightly less. If so, consumers will be more likely to choose green energy than if it is only slightly better on environmental grounds and if it costs far more. Individual preferences certainly matter. Across a reasonable range of imaginable differences in magnitudes, we would expect to see a great deal of heterogeneity across people, nations, and cultures. Some people do not much care about the environment, and the monetary figures will drive their choices. For other people, environmental protection is an important value, and such people may be willing to pay a great deal to make the environmentally preferred choice. On standard assumptions, people's decisions will depend on the relationship between economic incentives and underlying preferences.

The standard assumptions are not exactly wrong, but as behavioral economists have shown, they disregard important variables that do not involve strictly economic incentives. ${ }^{1}$ Some kind of choice architecture lies behind people's decisions, and that architecture may have large effects on what people choose. ${ }^{2}$ One question involves prevailing social norms. ${ }^{3}$ What choices are other people making, and why? If choosers know that most other choosers are selecting green energy, there will be an increase in the likelihood that they will themselves choose green energy. ${ }^{4}$ If, by contrast, environmentalists lament the fact that few people are choosing green energy, the result might well be to aggravate the very problem that environmentalists are seeking to solve, by drawing attention to, and thus reinforcing, a social norm that they hope to change. And if there is a widespread belief that reasonable and good people select environmentally preferable products, that norm will exert pressure in favor of green

\footnotetext{
${ }^{1}$ For a valuable collection, see THE BEHAVIORAL FoundaTIONS OF POLICY (Eldar Shafir ed., 2013).

${ }^{2}$ See Richard H. Thaler \& Cass R. Sunstein, Nudge: Improving Decisions About Health, WeAlth, AND HAPPINESS (2008).

${ }^{3}$ See Hunt Alcott, Social Norms and Energy Conservation, 95 J. PUB. ECON. 1082 (2011); Hunt Alcott \& Todd Rogers, The Short-Run and Long-Run Effects of Behavioral Interventions (Nat'l Bureau of Econ. Research, Working Paper No. 18492, 2012), available at https://files.nyu.edu/ha32/public/research/Allcott\%20and\%20Rogers\%202012\%20NBER\%20WP\%20\%20The\%20Short-Run\%20and\%20Long-Run\%20Effects\%20of\%20Behavioral\%20Interventions.pdf

${ }^{4}$ See Alcott, supra note, at 1082-95.

${ }^{5}$ Robert B. Cialdini et al., Managing Social Norms for Persuasive Impact, 1 SoC InfluenCE 3, 10-12 (2006).
} 
energy. ${ }^{6}$ Social norms may well lead behavior in a green or gray direction even in the face of significant economic incentives. ${ }^{7}$

Another question involves expressive considerations. Some consumers select green energy not because of a careful calculation that the environmental benefits justify the private costs, but because of a desire to express certain values ${ }^{8}$ or to act in accordance with their idealized self-perception. ${ }^{9}$ Many of those who purchase environmentally preferred vehicles seem to be responding largely to expressive considerations. They want to "make a statement." They may want to do so because of their conception of their identity ${ }^{10}$ or because they want their statement to be seen in public. ${ }^{11}$ Expressive considerations can of course point in different directions in accordance with prevailing norms. In some communities, purchase of green energy (and green products in general) is strongly favored on expressive grounds; in other communities, it is not favored or is even disfavored. ${ }^{12}$

While expressive considerations may involve people's self-understandings, they may also involve signaling. ${ }^{13}$ Consumers may wish to signal their preferences to others and that desire may influence their choices, as in cases of conspicuous conservation. ${ }^{14}$ Socially visible products, such as electric sports cars, are naturally more useful for status display than switching to green electricity, installing a high-efficiency heat pump in the

\footnotetext{
${ }^{6}$ See id. at 12 . Note in particular the finding that drawing public attention to the existence or pervasiveness of undesirable behavior can actually increase such behavior:

It is worthy of note that our most ineffective persuasive message simulated the sort of negatively worded, descriptive norm message that . . . is regularly sent by public health and community service officials regarding a wide variety of social problems. Our results indicate that appeals of this type should be avoided by communicators in their persuasive undertakings. Unfortunately, this is not always the case. . . For instance, after we reported the outcomes of the present study [showing the ineffectiveness of park signs containing negatively worded, descriptive normative messages] to park administrators, they decided not to change the relevant aspects of their signage. . . . We were disappointed — but, truth be told, not surprisedthat park officials weighted visitors' subjective responses more than our empirical evidence in their signage decision.

Id.

${ }^{7}$ It is possible, of course, that an emphasis on social norms will trigger adverse reactions and potentially resistance, perhaps especially among younger people. See the discussion of "deviant subcommunities" in Robert A. Kagan \& Jerome H. Skolnick, Banning Smoking: Compliance without Enforcement, in SMOKING Policy: LaW, Politics, AND Culture 69, 72 (Robert L. Rabin \& Stephen D. Sugarman eds., 1993).

${ }^{8}$ See ERIC POSNER, LAW AND SOCIAL NORMS (2004).

${ }^{9}$ See Lucia Reisch, Consumption, in Environmental Thought 217 (Edward A. Page \& John Proops eds., 2003), on motivations to consume.

${ }^{10}$ For relevant discussion, but not focused on environmental protection in particular, see GEORGE A. AKERLOF \& RACHEL KRANTON, IDENTITY ECONOMICS (2010).

${ }^{11}$ Vladas Griskevicius et al., Going Green To Be Seen? Status, Reputation, and Conspicuous Conservation, 98 J. PersonAlity \& SOC. Psychol. 392 (2010)

${ }^{12}$ On the diversity of social meanings, and their changes over time, see Lawrence Lessig, The Regulation of Social Meaning, 62 U. Chi. L. Rev. 943 (1995).

${ }^{13}$ See Griskevicius et al., supra note; Steven E. Sexton \& Alison L. Sexton, Conspicuous Conservation: The Prius Effect and Willingness to Pay for Environmental Bona Fides (June 30, 2011) (unpublished manuscript), available at $\mathrm{http}: / /$ works.bepress.com/sexton/11.

${ }^{14}$ See id.
} 
basement, or opting for car sharing. "Buying green" is often done for status reasons, while "behaving green" is usually less visible and status-laden. ${ }^{15}$ As we shall see, expressive considerations may also interact with law and policy. In particular, the law may affect the nature and even the sign of the signal.

People may also make a rapid, automatic judgment in favor of or against green energy, and that automatic judgment may motivate their behavior whatever the nature of a careful calculation of its own consequences. ${ }^{16}$ Denominating a product a green choice may be sufficient to create a kind of brand that sparks a "warm glow" for brand aficionados. ${ }^{17}$ That form of green branding and the associated emotional benefits may well have a large effect on intuitive judgments. In fact the power of green branding is such that it has been found to lead to a significant increase in the purchase of candy bars with green labels, especially among health-conscious purchases, even when those candy bars are not more healthy in any way. ${ }^{18}$ Of course social norms are likely to play a large part in producing such judgments.

Our principal topic here is the role of default rules. Defaults are settings that apply, or outcomes that stick, when individuals do not take active steps to change them. Default rules establish what happens if people do nothing at all. In the example with which we began, people are asked to make an active choice between green and gray energy. But it is easy to imagine a different approach, one that in which choice architects set a default rule in one direction or another, while allowing people to depart from it. In short, social outcomes might be automatically green.

Apart from creating a default rule, choice architects may or may not seek to influence people's choices. In fact there is a continuum of possible approaches, whose poles are active choosing (with neutral presentation) and firm mandates (with no ability to opt out), and whose multiple intermediate points include the following:

- active choosing accompanied by self-conscious framing or related influences (meant to encourage either green or gray),

- a pro-green default with costly opt-out,

- a pro-green default with costless opt-out,

- a pro-gray default with costless opt-out,

- a pro-gray default with costly opt-out.

\footnotetext{
${ }^{15}$ Martha A. Starr, The Social Economics of Ethical Consumption: Theoretical Considerations and Empirical Evidence, 38 J. SOCIO-ECON. 916 (2009).

${ }^{16}$ See Daniel Kahneman, Thinking, Fast and Slow (2011).

${ }^{17}$ Patrick Hartmann \& Vanessa Apaolaza Ibáñez, Green Value Added, 24 MARKETING INTELLIGENCE \& PLANNING 673 (2006)

${ }^{18}$ See Jonathon Schuldt, Does Green Mean Healthy? Nutrition Label Color Affects Perceptions of Healthfulness, HEALTH COMM. (2013), available at http://www.tandfonline.com/doi/pdf/10.1080/10410236.2012.725270.

${ }^{19}$ Eric Johnson \& Daniel Goldstein, Decisions By Default, in The Behavioral Foundations of Policy, supra note, at 417; C. L. Brown \& A. Krishna, The Skeptical Shopper: A Metacognitive Account for the Effects of Default Options on Choice, 31 J. CONSUMER RES. 529-539 (2004).
} 
Our goal is to explore the uses of green default rules. As we shall show, green defaults may well have major effects on environmental outcomes -- in some contexts comparable to the effects of mandates and bans, and potentially far larger than the effects of information, education, moral exhortation, and even significant economic incentives. ${ }^{20}$ If the goal is to protect the environment, and to save money in the process, default rules are an important tool in the regulatory repertoire, and they may be able to achieve a great deal more than other tools, including those that would cost taxpayers a great deal of money. Especially in a period in which the standard tools - mandates, bans, and economic incentives - sometimes face serious economic and political obstacles, default rules deserve careful attention.

One of the primary advantages of green defaults is that they can have beneficial effects while maintaining freedom of choice and hence respect for heterogeneity. Suppose, for example, that a relevant population contains a number of people who are facing serious economic difficulty. If so, and if green energy is more expensive than the alternative, it may well be important to allow consumers to opt out (at least if energy subsidies are unavailable). But a series of complexities arises by virtue of the fact that default rules are typically selected because they benefit choosers, not third parties; in the environmental context, externalities are frequently involved. This point suggests that the choice of default rules should turn on an assessment not only of consumer welfare but also of a set of other costs and benefits. If, for example, a green default would have modest costs for consumers, but produce significant social benefits from emissions reductions, it would (by hypothesis) be justified on cost-benefit grounds.

The largest point is that default rules with environmental consequences are pervasive, and they might be green, gray, or somewhere between. When existing defaults are relatively gray, it is not because nature so decreed, but because of emphatically human choices, and these might be otherwise. If public and private institutions seek to make progress on environmental problems - whatever their magnitude - they might well be able to do so by becoming far more self-conscious about selection of the appropriate defaults. One of our principal points is that default rules of multiple kinds are already in place, alongside other forms of choice architecture, and they have large effects on outcomes, both economic and environmental, even if they have not been subject to careful scrutiny. ${ }^{21}$

The remainder of this Article is organized as follows. In Part II, we offer an illustrative survey of green defaults, designed to establish their generality, their potential, and their impact. Part III explores why default rules matter, with an emphasis on the

\footnotetext{
${ }^{20}$ Raj Chetty et al., Active vs. Passive Decisions and Crowd out in Retirement Savings Accounts: Evidence from Denmark (Nat'l Bureau of Econ. Research, Working Paper No. 18565, 2012), available at http://www.nber.org/papers/w18565. For electricity products in Germany, see Josef Kaenzig et al., Whatever the Customer Wants, the Customer Gets? Exploring the Gap between Consumer Preferences and Default Electricity Products in Germany, 53 ENERGY POL'Y 311 (2013).

${ }^{21}$ Note that choice architecture may result from deliberate design or instead from invisible-hand mechanisms; there may be no architect. See Edna Ullmann-Margalit, Invisible-Hand Explanations, 39 Synthese 263 (1978).
} 
power of suggestion, the role of inertia, and loss aversion. Part IV examines non-sticky defaults, showing that in some cases, people will reject green defaults. Part V explores whether choice architects should select a green default (and which one to choose, if any), first on the assumption that consumers' interests are the only issue at stake, and second by introducing externalities. Part VI examines active choosing and various ways of influencing (while preserving) choice without the use of default rules. Building on the foregoing discussion, Part VII offers a general framework for choice architects to consider in selecting among the various options; the framework is designed to environmental questions but it has potentially broad applicability. Part VII concludes.

\section{Green Defaults: An Illustrative Survey}

Daily life is increasingly accompanied by the equivalent of green defaults, replacing grayer ones. Consider motion detectors that turn out the lights when people do not appear to be in the relevant room. In this way, motion detectors create the equivalent of an "off" default. Or consider appliance and computer settings that turn the relevant equipment off when it is not in use. If the default setting on office thermometers is turned down in winter, and up in summer, we should expect significant economic and environmental savings, at least if the default setting is not so uncomfortable that people will take steps to change it. ${ }^{22}$ Both policy and technology are making green defaults of this kind readily available. ${ }^{23}$ For purposes of illustration, we focus here on four domains in which choice architects may or may not select such defaults.

\section{A. Paper}

Human beings use a great deal of paper, and paper requires use of a large number of trees. Suppose that a private or public institution wants both to save money and to protect the environment by reducing its use of paper. It could, among other things, educate people about the potential value of use reductions ("just the facts"); attempt moral suasion by appealing to economic and environmental values; impose some kind of charge or fee for the use of paper; or impose ceilings on the total amount of paper used by relevant individuals or groups (with an inventive approach being a kind of cap-and-trade system).

But consider a much simpler intervention: Alter the institution's default printer setting from "print on a single page" to "print on front and back." A few years ago, Rutgers University adopted such a double-sided printing default. In the first three years of the new default, the result was to reduce paper consumption by well over fifty-five million sheets, which amounted to a 44 percent reduction, the equivalent of 4,650 trees. ${ }^{24}$ A natural field experiment at a large Swedish University also found a substantial

\footnotetext{
${ }^{22}$ Zachary Brown et al., Testing the Effects of Defaults on the Thermostat Settings of OECD Employees, 39 Energy Economics 128 (2013).

${ }^{23}$ For the available palette of default policies, see Eric J. Johnson et al., Beyond Nudges: Tools of a Choice Architecture, 23 MARKETING LETTERS 487 (2012).

24 See Print Management Information, RUTGERS.EDU, http://www.nbcs.rutgers.edu/ccf/main/print/transition.php (last updated April 11, 2012).
} 
reduction, with a significant and immediate effect in the form of a 15 percent drop in paper consumption, and with that effect staying stable over time. ${ }^{25}$

It is evident that if private and public institutions decided in favor of a simple change of the default, they would have a large impact on paper usage. Many people use far more paper than they need only because of the "single page" default; a change would produce significant savings at negligible costs in terms of convenience and changing reading habits. At least in the face of weak preferences, the default has a large effect, even when switching costs are negligible. ${ }^{26}$ Notably, that large effects can be found even though strong efforts to encourage people to use double-sided printing have essentially no impact. ${ }^{27}$ Also notably, the effect of the double-sided default has been found to be far larger than that of a ten-percent tax on paper products, which would produce a mere twopercent reduction. ${ }^{28}$

\section{B. Green Energy}

We began with a choice between utility suppliers. It is far too simple, of course, to suggest that the available possibilities fall in two dichotomous categories of "green" and "gray." There are multiple options, and the environmental and economic consequences of diverse sources of energy require careful investigation; disputes are easy to find. ${ }^{29}$ Recall that the very label "green" can affect consumers, even for candy bars, whether or not the underlying good or service is healthy or protective of the environment. ${ }^{30}$ For present purposes, it is sufficient to stipulate that from the environmental point of view, some sources are preferable to others, and consumers might want to consider environmental factors when choosing energy, especially if they can save (or do not lose) money at the same time.

Many jurisdictions do offer some kind of choice. In some nations (including the United States), people are generally defaulted into a particular source, with the option to opt out. Typically, the default is relatively gray (perhaps because some of the green options continue to be expensive). To use green energy, people have to seek out relevant information and choose it affirmatively. ${ }^{31}$ The deterrent effects of that requirement are large, even in circumstances in which people would give serious consideration to green options if presented with the choice unaccompanied by a default. What would be the

\footnotetext{
${ }^{25}$ See Johan Egebark and Mathias Ekström, Can Indifference Make the World Greener? (2013), available at http://www2.ne.su.se/paper/wp13_12.pdf

${ }^{26} \mathrm{Id}$.

${ }^{27}$ Id.

${ }^{28}$ Id. at 20.

${ }^{29}$ The literature is of course voluminous. For diverse views, see GODFREY BOYLE, RENEWABLE ENERGY: Power for a Sustainable Future (2012); Energy Systems And Sustainability (Bob Everett et al. eds., 2012); Roger E. Meiners et Al., The False Promise of Green Energy (2011); Ozzie Zehner, GREEN ILLUSIONS (2012).

${ }^{30}$ See note supra.

31 For one example, see Frequently Asked Questions, MASS ENERGY CONSUMERS ALLIANCE, http://www.massenergy.org/renewable-energy/FAQ (last visited April 4, 2013).
} 
effects of switching to a green default? The question has been examined through two natural experiments, involving actual behavior, and also a series of laboratory experiments. ${ }^{32}$

1. Actual behavior. In Germany, many people say that they would use green energy if presented with a choice, but very few consumers actually opt for green; in almost all communities, the green usage rate was for a long period under one percent (though it has significantly increased in recent years). ${ }^{33}$ Even when the green usage rate was generally close to zero, two communities showed usage rates well above 90 percent. The reason is simple: They used green defaults.

The first such community is Schönau in the Black Forest, consisting of about 2500 people and (notably) dominated by conservatives, with a weak Green Party (receiving only about five percent of recent ballots). ${ }^{34}$ In the aftermath of the Chernobyl disaster in the 1980s, a citizen referendum established an environmentally-friendly energy supply, in which the Schönau Power Company became the incumbent utility and many of the Schönau citizens became owners of the cooperative. That company promotes solar energy and places a great deal of reliance on renewables. Customers are allowed to opt out and to use other energy sources, but they have to find relevant information in order to identify alternatives. Almost no one opts out: In recent years, the opt out rate has been only slightly above zero percent.

The second natural experiment involves Energiedienst $\mathrm{GmbH}$, which supplies energy to an area in southern Germany. ${ }^{35}$ In 1999 , the company established three separate tariffs. The default was green, and it turned out to be eight percent cheaper than the previous tariff. The second option was less green but cheaper (by an additional eight percent) and the third was greener but more expensive (by an additional 23 percent). If customers did not respond, they would remain with the default. About 94 percent of customers so remained, with 4.3 percent switching to the cheaper tariff, and the rest switching either to the greener alternative or to a different supplier.

These results testify to the extraordinary power of defaults. Recall that elsewhere in Germany, the use of green energy was at the time of the study less than one percent, even though consumers said that they would be willing to pay a premium for it. But outside of the two areas just described, people were required affirmatively to select green energy, and overwhelmingly they did not. It is fair to speculate that at least within a large range, the default rule determines the kind of energy that people use.

\footnotetext{
${ }^{32}$ Daniel Pichert \& Konstantinos V. Katsikopoulos, Green Defaults: Information Presentation and Proenvironmental Behaviour, 28 J. ENVTL. PSYCHOL. 63 (2008), on which we draw throughout this section. A more recent experimental study in Germany is reported in Kaenzig et al., supra note.

${ }^{33}$ See Pickert \& Katsikoupoulos, supra note, at 64.

${ }^{34}$ Id. at 66.

${ }^{35}$ Id.
} 
2. Experiments. Experimental results should be taken with many grains of salt, because they may not predict actual behavior, ${ }^{36}$ but they can be informative, and they also find a large effect from green defaults. ${ }^{37}$ In one laboratory study, people were presented with a choice between two suppliers. The first, called EcoEnergy, was described in this way: "EcoEnergy sells clean energy, generated from renewable electricity sources. Contribute to climate protection and environmental protection!" The second, called Acon, was described in this way: "We offer low-priced electricity tariff-you cannot beat our prices. Save money with Acon!" The default turned out to matter a great deal. When Acon was the default, 57 percent of participants stuck with it, but when it was the alternative, only 32 percent of people chose it. ${ }^{38}$ Interestingly, about the same percentage of people chose Acon in a case of active choice.

A similar experiment found a significant disparity in economic valuations. ${ }^{39}$ Asked how much they would be willing to pay to switch to green energy, people gave a mean value of 6.59 euros. Asked how much they would be willing to accept to switch from green energy, they gave a median value of 13 euros. Interestingly, this difference precisely tracks the standard difference between willingness to pay and willingness to accept; the latter is usually double the former. ${ }^{40}$

A recent study based on 2009 household data found a remarkable gap between customer preferences and the products being offered as the average electricity mix in Germany. ${ }^{41}$ With regard to five alternative electricity production mixes offered, the thencurrent default ranked second to last in terms of consumer preferences - which were strongly in favor of renewable energy products. ${ }^{42}$ The finding attests to the real possibility that existing defaults may persist even if they do not reflect the preferences of the consumers whose choices are effectively determined by them. ${ }^{43}$

\section{Energy Efficiency}

Many consumers use products that are significantly less energy efficient than available alternatives. ${ }^{44}$ For public policy, a central question is whether and when they will to switch to products that are more efficient and less expensive (at least in the long-

${ }^{36}$ See George Loewenstein et al., Disclosure: Psychology Changes Everything, Annual Review of Economics (forthcoming 2014).

${ }^{37}$ Pickert \& Katsikoupoulos, supra note, at 67-68.

${ }^{38}$ Id. at $68-69$.

${ }^{39}$ Id. at 70 .

${ }^{40}$ See Richard H. Thaler, QUASI-RATIONAL ECONOMics (1993).

${ }^{41}$ Kaenzig et al., supra note.

${ }^{42}$ Note, however, that two years after the Fukushima disaster and the initiation of the German "Energiewende," most energy providers offer attractive "green energy" mixes and have greatly changed their supply policy. See Lucia Reisch, Verhaltensbasierte Elemente einer Energienachfragepolitik, in GRENZEN DER KONSUMENTENSOUVERÄNITÄT 139 (Jahrbuch Normative und institutionelle Grundfragen der Ökonomik, Vol. 12, 2013).

${ }^{43} \mathrm{See}$ below for discussion of inertia.

${ }^{44}$ See, e.g., THE ECONOMICS OF ENERGy EFFICIENCY: BARRIERS to COST-EFFECTIVE INVESTMENT (Eoin O’Malley et al. eds., 2004). 
run). And in some cases, people do have energy-efficient products, and it is possible that they will switch less energy-efficient products that are less expensive (at least in the short-run). Independent of the expense of the switch itself, does the default matter?

A series of experiments attempted to answer this question. ${ }^{45}$ People were asked to choose between two kinds of light bulbs. One is the efficient but costly Compact Fluorescent Light Bulb (CFLB); the other is the inefficient but inexpensive Incandescent Light Bulb (ILB). The choice between the two greatly matters. If every home in the United States changed merely one ILB to a CFLB, the result would be to save over $\$ 600$ million in annual energy costs, to eliminate greenhouse gas emissions equal to those of more than 800,000 cars, and to save energy that would light over three million homes annually. ${ }^{46}$

In the relevant studies, subjects were told that they were undergoing a significant amount of remodeling of their home and that the contractor had outfitted the light fixtures with either the ILB or the CFLB. Subjects were asked whether they wanted to switch, at no cost, to the alternative. They were also given a great deal of information about the costs and benefits of the two options. For example, the CFB would cost $\$ 11$ in electricity per 10,000 hours, whereas the ILB would cost $\$ 49$ per 10,000 hours. The CFB would cost $\$ 3$ per bulb whereas the ICB would cost $\$ 0.50$ per bulb. ${ }^{47}$

The central finding is that the default greatly mattered. When energy-inefficient ICBs were the default, they were chosen nearly 44 percent of the time. When the CFLB was the default, the ICB was chosen only 20.2 percent of the time. ${ }^{48}$ The disparity is especially noteworthy in view of the fact that in the relevant experiments, people were not in the standard real-world situation of having to overcome inertia and to make a change. They were asked, more simply, whether they would do so, and in the sense they were forced to choose. If they had the option of postponing the decision and simply sticking with the status quo, the disparity would undoubtedly be larger.

\section{Smart Grids}

Smart grid technology is of considerable interest in many nations, ${ }^{49}$ and in Germany in particular, it is a prerequisite for the radical expansion of the share of renewable energy that is needed to realize the German "Energiewende" (a transition in the uses of energy). Such technology has the potential to provide a better balance of the supply and demand of electricity and to make the grid more flexible, efficient, and reliable. In particular, smart meters have increasingly been seen, by the public and private sectors alike, to be useful tools to develop smart energy use patterns through the

\footnotetext{
${ }^{45}$ Isaac Dinner et al., Partitioning Default Effects: Why People Choose Not to Choose, 17 J. Experimental Psychol: Applied 332 (2011).

${ }^{46}$ See id.

${ }^{47}$ Id.

${ }^{48} I d$.

${ }^{49}$ See, e.g., Peter Fox-Penner, Smart Power: Climate Change, the SMart Grid, AND the Future of EleCtRic Utilities (2012).
} 
provision of immediate feedback. ${ }^{50}$ The explicit binding goal of the European Union's "Third European Energy Liberalization Package" is that by 2020, smart meter systems are installed in 80 percent of households. ${ }^{51}$ But there are obstacles to achievement of this goal, including data privacy concerns and perceived risks of reduced home comfort (part of the electricity consumption is remote controlled by the energy provider). As a result, consumers are reluctant to accept this new technology in their homes, and the 80 percent target currently seems to be a distant prospect. ${ }^{52}$

If the goal is to get close to the target, what might be done? A recent experimental study based on a nationwide panel in Denmark shows that the implied default greatly affects consumer behavior. More specifically, the acceptance rate to install a smart meter is significantly higher if offered as an "opt-out" frame ("No, I would not like to have a smart meter with remote control installed in my home") than as an opt-in frame. ${ }^{53}$ The study confirms that the framing of the question, and the implied default, have a substantial impact on the share of a population that accepts Smart Grid installation; with this finding in mind, the authors urge "that campaigners therefore should choose a framing only after careful consideration." 54

\section{Why Default Rules Matter ${ }^{55}$}

Why do default rules have such a large effect on outcomes ${ }^{56}$ ? There appear to be three principal contributing factors; each of them has distinctive characteristics in the context of green defaults.

1. Suggestion and endorsement. The first factor involves an implicit suggestion or endorsement on the part of those who have devised the default rule. ${ }^{58}$ Suppose that choice

\footnotetext{
${ }^{50}$ See id.

${ }^{51}$ Directive 2009/72/EC of the European Parliament and of the Council of 13 July 2009 concerning common rules for the internal market in electricity and repealing Directive 2003/54/EC (Text with EEA relevance), Official Journal of the European Union, 14.8.2009. L 211/ p. 91; see also INSTITUTE FOR ENERGY \& TRANSPORT JOINT RESEARCH CENTRE, http://ses.jrc.ec.europa.eu/ (last updated April 4, 2013).

${ }^{52}$ Austrian ENERgy Agency, European SMART METERING LANDSCAPE RePORT (2011), available at http://www.piio.pl/dok/European_Smart_Metering_Landscape_Report.pdf.

${ }^{53}$ Folke Ölander \& John Thøgersen, Informing or nudging, which way to a more effective environmental policy?, in MARKETING, FoOD AND THE CONSUMER 141 (Joachim Scholderer \& Karen Brunsø eds., 2013).

${ }_{55}^{54}$ Id. at 151.

${ }^{55}$ This section has an overlap with the more general discussion in Cass R. Sunstein, Deciding By Default (2013) (unpublished manuscript).

56 See, e.g., William G. Gale, J. Mark Iwry \& Spencer Walters, Retirement Savings for Middle- and Lower-Income Households: The Pension Protection Act of 2006 and the Unfinished Agenda, in AUTOMATIC 11, 13-14 (William G. Gale et al. eds., 2009); Isaac Dinner et al, Partitioning Default Effects, supra note; Gabriel D. Carroll et al, Optimal Defaults and Active Choices, 124 Q. J. ECON. 1639, 1641-43 (2009).

${ }^{57}$ For good discussions, see Eric Johnson \& Daniel Goldstein, Decisions by Default, in THE BEHAVIORAL Foundations of POLICY, supra note, at 417; Jeffrey Brown et al., The Downside of Defaults (2011) (unpublished manuscript), available at http://www.nber.org/programs/ag/rrc/NB1101\%20Brown,\%20Farrell,\%20Weisbenner\%20FINAL.pdf
} 
architects, whether private or public, have explicitly chosen a green default. If so, choosers may believe that they have been given an implicit recommendation (perhaps from a private institution, perhaps from public officials), and that they should not reject it unless they have reliable private information that would justify a change. If the default choice is double-sided printing or green energy, it is tempting to think that experts, or sensible people, believe that this is the right course of action. Those who are deciding whether to opt out might trust the choice architects well enough to follow their lead. Many people appear to think that the default was chosen by someone sensible and for a good reason. Especially if they lack experience or expertise and/or if the product is highly complex and rarely purchased, they might simply defer to what has been chosen for them. ${ }^{59}$ The point suggests that default rules are less likely to have an effect when people consider themselves to be experienced or expert, and indeed there are findings to this effect among environmental economists, who reject selected defaults. ${ }^{60}$

Outside of the environmental context, there is strong evidence that a lack of information on the part of choosers, including a lack of information about alternatives, helps to account for the power of defaults. ${ }^{61}$ In one study (involving savings behavior), over half of those who stuck with the default specifically mentioned an absence of private information as one of their reasons for doing so. ${ }^{62}$ An implication of this explanation is that if choosers do not trust the choice architect, in general or in the particular instance, they will be far more likely to opt out. And indeed, there is evidence for this proposition as well. ${ }^{63}$ If choice architects select a green default for reasons that are perceived as selfserving, elitist, preachy, or foolish, we would expect to see an increase in the rate of optout. Green defaults are more likely to stick if choosers trust those who have selected them, or at least perceive no reason to distrust them.

2. Inertia. The second explanation involves inertia and procrastination (sometimes described as "effort" or an "effort tax" ${ }^{\text {"64 }}$. To change the default rule to either green or gray, people must make an active choice to reject that rule. They have to focus on the

58 See Craig R.M. McKenzie, Michael J. Liersch \& Stacey R. Finkelstein, Recommendations Implicit in Policy Defaults, 17 Psychol. SCI. 414, 418-19 (2006); Brigitte C. Madrian \& Dennis F. Shea, The Power of Suggestion: Inertia in 401(k) Participation and Savings Behavior, 116 Q. J. ECON. 1149, 1182. Of course it is not true that all defaults are chosen because they produce the best outcomes for people.

${ }^{59}$ People might also have experienced for themselves the positive outcomes of controversial regulatory decisions that they might not have endorsed ex ante. Examples include smoking bans for bars and restaurants that have been imposed in the US and in Europe in the 2000s - in the face of industry opposition. Yet polls today show a high ex post agreement with these bans. Citing such examples, Elke Weber concludes that "query theory and such examples suggest that policy makers may sometimes be well advised to shape and lead public opinion rather than follow it." Doing the Right Thing Willingly, in The Behavioral Foundations of Public Policy, supra note, at 380, 393.

${ }^{60}$ Asa Lofgren et al., Are Experienced People Affected by a Pre-Set Default Option - Results from a Field Experiment, $63 \mathrm{~J}$ Env Economics and Management 66 (2012).

${ }^{61}$ See Brown et al., supra note.

${ }^{62}$ See id.

${ }^{63}$ See David Tannenbaum \& Peter Ditto, Information Asymmetries in Default Options 11-17 (unpublished manuscript) (2012) available at https://webfiles.uci.edu/dtannenb/www/documents/default\%20information\%20asymmetries.pdf.

${ }^{64}$ See Johnson and Goldstein, Decisions By Default, supra note, at 420-21. 
relevant question, which is whether how they should trade off environmental, economic, and perhaps other goods. Especially but not only if the question is difficult or technical, and if the tradeoff is complex or morally charged, it may be tempting to defer the decision or not to make it at all. In view of the power of inertia and the tendency to procrastinate, people may simply continue with the status quo. ${ }^{65}$

A striking example can be found in Germany. While increasing energy prices are headlines news in German media, and are causing considerable concern to consumers, most households remain in the basic tariff of the energy provider. This is so even though the basic tariff is usually more expensive than one fitting the household's actual use patterns and may also be more expensive than green energy. ${ }^{66}$ Only $22 \%$ of German households have switched their tariff or provider in the past two years - strong evidence of the power of inertia. ${ }^{67}$ Recall as well that in Germany, citizens appear to be defaulted into a form of energy use that the vast majority of Germans reject. ${ }^{68}$

In many cases involving environmental values, the decision whether to select green energy involves some thinking, some risk, and a potentially complex (and morally charged) assessment of economic and environmental considerations. The choice of an electricity provider is not exactly intuitive; it may well be cognitively demanding. The default rule might stick simply because people do not want to engage in that thinking, take that risk, or make that tradeoff. Studies of brain activity find that when decisions are complex and difficult, people are more likely to stick with the default. ${ }^{69}$ Even if people in some sense want to investigate the issue and possibly to make a change, they might decide that they will do so tomorrow - and tomorrow never comes.

Consider in this regard the finding that a default thermostat setting has a significant effect on OECD employees. ${ }^{70}$ A $1 \mathrm{C}$ degree decrease in the default caused a significant reduction in the average chosen setting, apparently because most employees did not much care about the new default, and hence did not take the time to change it. Small as it was, the cost of that effort did not justify the bother. This interpretation is supported by the remarkable finding that when the default setting was reduced by $2 \mathrm{C}$ degrees, the reduction in the average chosen setting was actually smaller, apparently because

\footnotetext{
${ }^{65}$ On choice avoidance, see Sheena S. Iyengar, Wei Jiang \& Gur Huberman, How Much Choice is Too Much?: Contributions to 401(k) Retirement Plans, in Pension Design and Structure: New Lessons FROM BehaVIORAL FinanCE (Olivia S. Mitchell \& Stephen P. Utkus eds., 2005).

${ }^{66}$ See regular product tests and price comparisons of energy providers offers conducted by the "Stiftung Warentest," available at www.test.de; see, e.g., Stiftung Warentest empfiehlt Versorgerwechsel, STIFTUNG WARENTEST (November 20, 2012), http://www.test.de/presse/pressemitteilungen/Hoehere-StrompreiseStiftung-Warentest-empfiehlt-Versorgerwechsel-4472100-0/.

67 Infas $\quad$ Energiemontor 2012, available at http://www.infas.de/fileadmin/images/aktuell/infas_Abb_Energiemarktmonitor.pdf.

${ }^{68}$ See note supra.

${ }^{69}$ S. Fleming, C.L. Thomas, R.J. Dolan, Overcoming status quo bias in the human brain, Proceedings of the National Academy of Science of the United States of America 107 (2010) 6005-6009.

${ }^{70}$ See Zachary Brown et al., Testing the Effects of Defaults on the Thermostat Settings of OECD Employees, 39 Energy Economics 128 (2013).
} 
sufficient numbers of employees thought that it was too cold, and returned the setting to the one that they preferred. ${ }^{71}$

In this case, the reason for the effect was probably inertia, not suggestion. The $1 \mathrm{C}$ degree decrease was a bit colder that the preferences of OECD employees, but not enough to justify a change. But with a $2 \mathrm{C}$ degree decrease, the underlying preference manifested itself in restoration of the original status quo. The general lesson, to which we will return, is that in the face of strong preferences, the default is less likely to stick, which gives choice architects greater room to maneuver when they make small changes rather than large ones.

3. Reference point and loss aversion. A third and especially interesting explanation stresses the fact that the default rule establishes the reference point for people's decisions. Recall in this regard the behavioral finding of loss aversion. People dislike losses far more than they like corresponding gains, ${ }^{72}$ and whether a loss or a gain is involved does not come from nature or from the sky. The default rule determines what counts as a loss and what counts as a gain.

To appreciate the power of loss aversion and its relationship to default rules, consider an illuminating study of teacher incentives. ${ }^{73}$ Many people have been interested in encouraging teachers to do better to improve their students' achievements. The results of providing economic incentives are decidedly mixed; many of these efforts have failed. ${ }^{74}$ But the relevant study enlists loss aversion by resetting the default. The authors gave teachers money in advance and told them that if students did not show real improvements, the teachers would have to give the money back. The result was a significant increase in math scores - indeed, an increase equivalent to a substantial improvement in teacher quality. The underlying idea here is that losses from the status quo are especially unwelcome, and people will work hard to avoid those losses. ${ }^{75}$

Return in this light to default rules and the question of energy efficiency. Suppose that as compared to the gray (energy-inefficient) choice, the green option costs $\$ 200$

${ }^{71} \mathrm{Id}$.

72 See Richard H. Thaler, Daniel Kahneman \& Jack L. Knetsch, Experimental Tests of the Endowment Effect and the Coase Theorem, in Richard H. THALER, QUASI RATIONAL ECONOMICS 167, 169 (1994); A. Peter McGraw et al, Comparing Gains and Losses, 21 PsychOL. SCI. 1438, 1444 (2010). Vivid evidence of loss aversion can be found in David Card and Gordon B. Dahl, Family Violence and Football: The Effect of Unexpected Emotional Cues on Violent Behavior, 126 Q. J. ECON. 103, 105-06, 130-35 (2011) (finding an increase in domestic violence after a favored team suffers from an upset loss in football).

${ }^{73}$ See Roland Fryer et al., Enhancing the Efficacy of Teacher Incentives through Loss Aversion (Nat'1 Bureau of Econ. Research, Working Paper No. 18237, 2012), available at http://www.nber.org/papers/w18237.pdf.

${ }^{74}$ See id.

${ }^{75}$ For a valuable discussion of loss aversion and its importance, see Tatiana A. Homonoff, Can Small Incentives Have Large Effects? The Impact of Taxes versus Bonuses on Disposable Bag Use? (March. 27, 2013) (unpublished manuscript), available at http://www.princeton.edu/ homonoff/THomonoff JobMarketPaper. Homonoff shows that small, five-cent tax on the grocery bags, in the District of Columbia, has had a significant effect in reducing grocery bag use - but that a small, five-cent bonus for using reusable bags had essentially no effect. 
more upfront but saves $\$ 210$ over a period of five years. If the gray option is the default, people are likely to focus on the immediate loss of $\$ 200$, and they will be highly reluctant to incur that loss. Perhaps the $\$ 210$ savings will overcome their reluctance -- but the immediate \$200 loss will likely loom large. If, by contrast, the green option is the default, people are more likely to focus on the eventual loss of $\$ 210$, and they will be highly reluctant to incur that loss. In the environmental context, loss aversion may have an especially significant effect, certainly in the case of green defaults: People may well feel a pang of conscience, or anticipatory regret, if they are contemplating rejection of a green default.

In this respect, the default may well interact with, and help to establish or reinforce, prevailing social norms. Recall that some people make environmentally friendly choices because they want to "make a statement." If opting out produces environmental as well as economic harm, it may entail a statement that consumers do not want to make - and this is so even if they would not have opted in.

\section{When Default Rules Do Not Stick}

In some cases, people are willing to switch the default and possibly to reject the greener outcome. Recall that in the face of a $2 \mathrm{C}$ degree decrease in the default setting, many OECD employees took action to turn up the temperature. ${ }^{76}$ Note as well that when experienced people - environmental economists attending a conference - were presented with a default number for carbon dioxide offsets for flying, they were unaffected by that number. ${ }^{77}$ And in the study of energy-efficient light bulbs, the default rule was sticky, but not remarkably so. Even when it was the default, the energy-inefficient light bulb was rejected by about 56 percent of choosers. ${ }^{78}$ We could easily imagine populations that would likely reject the energy-efficient choice in equal or higher numbers, especially if the less efficient option cost a great deal less, and if in that population, environmental considerations did not loom large.

When default rules do not stick, the reason is usually straightforward: People have clear preferences that run counter to them. If preferences are clear, people are less likely to be influenced by the endorsement in the default rule. Inertia may well be overcome. Loss aversion will be far less relevant, in part because the clear preference helps define the reference point from which losses are measured.

Suppose that consumers are defaulted into an energy source that costs 50 percent more than the alternative. Unless social norms or inertia are particularly strong, consumers will reject that default. For supportive evidence, consider both the evidence

\footnotetext{
${ }^{76}$ Brown et al., supra note.

${ }^{77}$ Lofgren et al., supra.

${ }^{78}$ Recall, however, that the study was a laboratory experiment, not a randomized trial. If people actually had to take steps to change the default - rather than merely answering questions about whether they would do so - the switch rate would likely have been smaller.
} 
presented above and also a study in the United Kingdom, which found that most people opted out of a savings plan with an unusually high (and therefore unattractive) default contribution rate (12 percent of before-tax income). ${ }^{79}$ Only about 25 percent of employees remained at that rate after a year, whereas about 60 percent of employees shifted to a lower default contribution rate. Notably, people with lower incomes were more likely to stay at the unusually high contribution rate. ${ }^{80}$ Similar findings have been made elsewhere, with growing evidence that those who are less educated, and less sophisticated, are more likely to stick with the default. ${ }^{81}$ Note as well the finding that while school children could well be nudged (through the functional equivalent of default rules) into healthier choices, researchers were not able to counteract the children's strong preference for (unhealthy) French fries. $^{82}$

The clear implication is that extreme or highly unwelcome defaults are less likely to stick. It follows that green defaults that are perceived as foolish, wrong, harmful, expensive, or the imposition of some high-minded environmentalist elite, may well be rejected by many consumers. A more puzzling and somewhat troubling implication, based on the lower incomes of those who stayed with the default in the savings study described above, is that default rules may be more sticky for low-income workers than for their higher-earning counterparts. One reason may be that low-income workers have a great deal to worry about, ${ }^{83}$ and so are less likely to take the trouble to think through and to alter the default rule. An "effort tax" may seem especially high, and have an especially large adverse effect on, people who are already facing a large number of decisions and costs. ${ }^{84}$ Supportive evidence can be found in Germany, where low socio-economics status (SES) households tend to stay with their energy provider while higher SES households tend to switch. ${ }^{85}$

This point suggests that a costly green default may have a regressive impact, both because poor people have less money and because they may well be especially likely to stick with it. And indeed, there is general evidence that when people are highly informed and experienced, and hence know what they want, they are far less likely to be affected by the default rule. ${ }^{86}$ One reason is that the effort tax is worth incurring. Another reason is

79 See John Beshears et al, The Limitations of Defaults 8 (Sept. 15, 2010) (unpublished manuscript), available at http://www.nber.org/programs/ag/rrc/NB10-02,\%20Beshears,\%20Choi,\%20Laibson, $\% 20$ Madrian.pdf.

${ }^{80} I d$.

${ }^{81}$ Jeffrey Brown et al., The Downside of Defaults (unpublished manuscript 2011), available at http://www.nber.org/programs/ag/rrc/NB11-01\%20Brown,\%20Farrel1,\%20Weisbenner\%20FINAL.pdf

${ }^{82}$ See David J. Just and Brian Wansink, Smarter Lunchrooms: Using Behavioural Economics to Improve Meal Selection, CHOICES, 24(3) (2009), available at: http://www.choicesmagazine.org/magazine/pdf/article_87.pdf

${ }^{83}$ See AbHiJt BAnerJee \& Esther Duflo, Poor ECONomics (2010); Shah et al., Some Consequences of Having Too Little, supra note.

${ }^{84}$ See the discussion below.

${ }^{69}$ Infas $\quad$ Energiemontor available at http://www.infas.de/fileadmin/images/aktuell/infas_Abb_Energiemarktmonitor.pdf.

${ }^{86}$ See Åsa Lofgren et al., Are Experienced People Affected by a Pre-Set Default Option-Results from a field experiment, 63 J. ENVTL. ECON. \& MGMT. 66 (2012). 
that highly involved and competent "market mavens" actually enjoy searching extensively and making their choice independently of defaults. Since "the consumer" does not exist in the abstract, there have been calls for a more group-specific policy design that takes the relative level of consumer competence into consideration, and in particular that distinguishes among confident, vulnerable, and responsible consumers. ${ }^{87}$ Such distinctions may bear on the selection of personalized default rules, taken up below.

\section{Green or Gray?}

We now turn to the normative question. Which default rule should choice architects select?

\section{A. Consumers (Without Externalities)}

For purposes of simplification, begin with the case in which the only concern is the welfare of the chooser and there are no (or only modest) externalities. The preferred approach is to select the default rule that reflects what most people would choose if they were adequately informed. ${ }^{88}$ If we know that a particular default rule would place people in the situation that informed people would select, we have good reason to select that default rule (with the understanding that those who differ from the majority may opt out).

In the easiest cases, the answer is entirely clear once we specify the likely effects of the options in question. If green energy would both cost less and reduce environmental harm, it is safe to say that most informed people would choose it. ${ }^{89}$ It should certainly be default. Under the specified circumstances, those who want consumers to make different choices will not find it easy to explain their views. Indeed, some options should be ruled out of bounds because they are obviously in no one's interest. Now suppose that the tradeoff is not so self-evident, but that we have reason to believe that 80 percent of people, given a great deal of information, would choose green energy. This might be the case if either (1) green energy is far better on environmental grounds but only very slightly more expensive or (2) the relevant population is known to have strong environmental commitments. In either case, there is a strong reason to favor automatic enrollment in green energy. But if gray energy would cost significantly less than green,

\footnotetext{
${ }^{87}$ See Hans Micklitz et al., The Consumer - Confident, Vulnerable or Responsible? Plea for a Target Group Specific Strategy in Consumer Policy, Scientific Advisory Council on Consumer and Food Policy, 2011.

${ }^{88}$ See N. Craig Smith, Daniel G. Goldstein, and Eric J. Johnson, Smart Defaults: From Hidden Persuaders to Adaptive Helpers 15-16 (INSEAD Bus. Sch., Working Paper No. 2009/03/ISIC, 2009), available at $\mathrm{http}: / / \mathrm{ssrn} . \mathrm{com} / \mathrm{abstract}=1116650$.

${ }^{89}$ There are strong indications that this is the case in Germany, and demand for green energy has in fact risen dramatically in recent years. [see: Federal Ministry for the Environment, Nature Conservation an Nuclear Safety of Germany, Strategic and Economic Aspects of the Energiewende Unit (E I 1), Development of Renewable Energy Sources in Germany 2011, December 2012, available at: http://www.erneuerbare-

energien.de/fileadmin/Daten_EE/Bilder_Startseite/Bilder_Datenservice/PDFs_XLS/20130110_EEiZIU_E _PPT_2011_FIN.pdf.
} 
and if it would be only slightly worse on environmental grounds, a gray energy default would seem best.

To be sure, it might well be necessary to do a great deal of empirical work in order to identify the approach that informed people would choose. (As we shall see, this is a point in favor of active choosing.) The idea of "informed" choice might also raise hard conceptual questions. For reasons that behavioral economists have emphasized, ${ }^{90}$ people may err even if they have a great deal of information. They may, for example, display unrealistic optimism or discount the long-term ${ }^{91}$; the latter point bears especially on choices in the areas of energy and environmental protection. If informed choosers show systematic biases, it may not make a great deal of sense to base default rules on what appear to be informed choices. On the other hand, any effort to build correction of such biases into the very idea of the informed chooser creates a risk, which is that the enterprise will involve identification of what the choice architect believes to be the right choice on the merits - in which case the chooser, as an agent, tends to drop out of the analytic picture. The best solution is probably to rely on what informed choosers actually do, while also allowing correction if their choices can clearly be shown to be against their interest, perhaps because of some kind of behavioral bias.

On this count, actual evidence -- about what informed choosers do -- is extremely important. It would be useful to assemble information about the level of opt-out under various alternatives. ${ }^{92}$ Perhaps experiments or pilot programs would provide such information. ${ }^{93}$ If only two percent of people opt out if green energy is the default, and 50 percent opt out if gray energy is the default, we have reason to believe that green energy is better.

Of course it is possible that majority rule is too crude. Suppose that there are two default rules, green and gray. Suppose that 55 percent of informed people would be relatively indifferent between green and gray, but would slightly prefer green. Suppose too that because of their unusual situation (perhaps they are poor), 45 percent of people would strongly prefer gray. It is probably best to select gray, because almost half of the population would much like it, and the (narrow) majority only cares a little bit. The example shows that it is important to ask not only about which approach would be preferred by informed people, but also about the intensity of their preferences.

\section{B. Consumers and Third Parties}

\footnotetext{
${ }^{90}$ See Cass R. Sunstein, The Storrs Lectures: Behavioral Economics and Paternalism, YALE L.J. (forthcoming 2013).

${ }^{91} \mathrm{Id}$

92 See THALER \& SUNSTEIN, supra note.

${ }^{93}$ The Behavioral Insights Team in the United Kingdom is actively engaged in such projects, including in the domain of energy. See Behav. Insights Team, Behaviour Change And EnERgy Use (2011), available https://www.gov.uk/government/uploads/system/uploads/attachment_data/file/60536/behaviour-changeand-energy-use.pdf.
} 
In the environmental context, externalities are pervasive; they may well be the principal motivation for a green default rule. Choosers may also face a collective action problem. Asked individually, they might rationally select gray energy, but they might prefer green energy if everyone else were doing so as well (a possibility that argues for a firm mandate rather than a mere default rule). If choice architects are deciding among defaults in the presence of externalities and collective action problems, they must investigate the full set of costs and benefits, not only the welfare of choosers. ${ }^{94}$ If a default rule turned out to stick, what would be the costs and what would be the benefits ${ }^{95}$ ?

Consider the question whether the default rule should favor one-sided paper or two. We would need to know something about the relevant population to know which of these would be best from the individual standpoint. In the abstract, the answer is not obvious. Perhaps choosers are generally indifferent as between one-sided and two-sided copies; perhaps they strongly favor one or the other. If choice architects have no idea, they might ask people to choose. But it is easy to imagine situations in which individuals are relatively indifferent and the externalities are decisive. The best approach would be to quantify those effects. If the effects are significant, they will argue strongly for a doublesided default even if the majority of choosers would prefer single-sided. It is of course relevant that those who dislike the default can opt out. And it is true that if the externalities are especially large, a mandate becomes to look more attractive and justified on economic and ethical grounds.

Or return to the case of green energy. Even if most choosers would select gray because it is less expensive, green might be the better default if it would avoid significant costs. Perhaps certain energy sources produce far less in the way of air pollution. If so, there would be strong reason to select a default rule that reduces such pollution. Suppose that we focus narrowly on greenhouse gas emissions. In recent years, a great deal of work has been done to attempt to specify the social cost of carbon (SCC). ${ }^{97}$ In 2010, a technical working group in the United States settled on an SCC of about \$23 (2013 dollars) ${ }^{98}$; in 2013 , the number was updated to about $\$ 35 .{ }^{99}$ We could easily imagine cases in which the avoidance of greenhouse gases would produce significant gains, so that a green default would be simple to justify even if it turned out to be more expensive for users. Ideally, choice architects would monetize all of the relevant costs associated with relevant energy

${ }^{94}$ For a valuable discussion, see Eric Johnson \& Daniel Goldstein, Decisions by Default, supra note.

${ }^{95}$ Distributional issues may of course matter as well - a point to which we will return.

${ }^{96}$ On some of the foundational questions, see MATTHEW ADLER, WELL-BEING AND FAIR DistribUtion: BEYOND COST-BENEFIT ANALYSIS (2011)

${ }^{97}$ See Interagency Working Grp. on Social Cost of Carbon, TeChnical Support Document: SOCIAL COST OF CARBON FOR REgULATORY IMPACt ANALYSIS UNDER EXECUTIVE ORDER 12866 (2010), available at http://www.epa.gov/oms/climate/regulations/scc-tsd.pdf. For an illuminating critique, see William Nordhaus, Estimates of the Social Cost of Carbon (October 18, 2011) (unpublished manuscript), available at $\mathrm{http}: / /$ dido.econ.yale.edu/P/cd/d18a/d1826.pdf

${ }^{98}$ See note supra.

${ }^{99}$ INTERAGENCY WORKING GRP. ON SOCIAL COST OF CARBON, TECHNICAL SUPPORT DOCUMENT: UPDATED SOCIAL COST OF CARbON FOR REgUlatory IMPACt ANALYSIS UNDER EXECUTIVE ORDER 12866 (2010), available http://www.whitehouse.gov/sites/default/files/omb/inforeg/social_cost_of_carbon_for_ria_2013_update.pdf 
users and set a default rule accordingly. ${ }^{100}$ Of course it is true that the assessment could create serious empirical challenges both in monetizing the relevant benefits and in projecting the level of opt-out.

As we have suggested, distributional issues may be relevant and important as well. Suppose, for example, that the cost-benefit analysis argues in favor of a green default, but that the selection of that default imposes net costs on consumers, including poor people. Suppose too that poor people are unlikely to opt out, perhaps because they are busy and occupied with other matters, perhaps because they are not confident that opting out makes best sense or because they fear - unnecessarily - that they will lose supply. If poor people would in fact be net losers, but would not opt out, the argument for a green default is weakened. If it is chosen, it may be important to explore the possible of financial subsidies for those who pay for it or to make the possibility of opt-out both salient and clear, at least if the latter can be achieved without endangering the goals that led to the default rule in the first instance.

\section{Active Choosing, Influenced Choice, and Personalized Defaults}

As we have suggested, choice architects have a large number of options, and they might dispense with a default rule entirely. For example, they might require people to make an active choice between green and gray options. Markets provide an array of active choices, and while the relevant architecture affects what consumers ultimately select, no default rule need be involved. Consider a "menu approach" or "grocery store approach" to the question of energy efficiency and fuel economy, in which people have a wide range of options, and they may select what best fits their preferences and situations (perhaps with legal restrictions on the most energy-inefficient possibilities). The menu or grocery store approach captures a great deal of the current situation. For example, there is active competition in the markets for motor vehicles and appliances, and energy efficiency is one dimension along with producers compete. No default rule is generally in place for private households.

\section{A. Neutrality and Active Choice}

With active choices, people are required to make an actual decision among the various options; they are not defaulted into any particular alternative. In the environmental domain, active choosing has a number of significant advantages, certainly over opt-in (requiring consumers to reject the default to arrive at the environmentally preferred result), and sometimes over opt-out as well.

1. Green by choice? The first point is that because an actual decision is required, active choosing overcomes inertia. Suppose that people are using gray energy not because they have affirmatively decided to do so, but because gray is the default, and they have not focused on the options. If inertia (and procrastination) are playing a significant role,

\footnotetext{
${ }^{100}$ As we have noted, externalities might justify a mandate rather than a default rule.
} 
active choosing may be far better than opt-in. Here is another way to put the point: With active choosing, people are required to incur effort costs that might otherwise lead them to focus on other matters. As a result, active choosing promotes learning, which might be especially valuable in this context.

Active choosing is also a safeguard against uninformed or self-interested choice architects. When choice architects lack relevant information, so that the chosen rule might be harmful to some or many, there are significant advantages to active choosing. If public officials are biased or inadequately informed, and if the default rule is no better than a guess, that rule might lead people in the wrong direction. We have seen that the choice between green and gray defaults may well create serious empirical challenges. In the face of those challenges, the best route might be to ask consumers what they would like (again, in the absence of significant externalities).

It is also important to see that a default rule is most feasible to implement when consumer choice already occurs, or can easily be made to occur, on some kind of interface (e.g., on paper or electronically). In such cases, choice architects should be able to establish a default rule by placing it on the existing interface, or by adopting an interface on which the default rule is established. But in other cases, that task may be far more challenging. Suppose, for example, that choice architects, focused on environmental protection and public health, are considering the creation of default rules for consumer choices at appliance stores, grocery stores, and concession stands at movie theaters. In such settings, is it even possible to enlist default rules? How? To be sure, choice architecture might be devised to make particular choices more accessible or salient, and the relevant design might well have significant effects on what people select. "'Green design," exploiting accessibility and salience, can be seen as a close cousin of default rules, but it is not the same thing.

Quite apart from this point, sensible default rules are hard to establish for many routine decisions, simply because of the many considerations that diverse people take into account in making those decisions. For example, the decision whether to rent a car or take a train, bus, or airplane for travel raises far more difficulty than the decision whether to use one or two-sided printing. Potentially relevant factors include consumer cost, consumer safety, near-term externalities (e.g., traffic congestion), long-term externalities (e.g., GHG pollution), speed of travel, flexibility of departure and arrival time, consumer abilities (e.g., ability to drive), and consumer tastes. It might well be prohibitively costly to organize any interface to establish workable default rules that reliably balance those interests for the relevant population. For this reason, active choosing seems much better. To be sure, technological innovations may eventually reduce that problem, not least through the use of personalization. ${ }^{102}$

There is also a strong argument against a default rule, and in favor of active choosing, when self-interested private groups are calling for government to select it even

\footnotetext{
${ }^{101}$ See Brian Wansink, Slim By Design (2014).

${ }^{102}$ See infra.
} 
though it would not benefit those on whom it is imposed. In the environmental context, it is easy to imagine a high degree of interest-group jockeying, in which self-interested producers argue vigorously on behalf of a default rule that would benefit them; the choice of energy sources may well invite this kind of jockeying. Active choosing would reduce the risks on this count, because it would not allow public officials to default consumers into any particular source. Finally, and in some cases most important, active choosing appropriately handles diversity. As compared with either opt-in or opt-out, active choosing can have major advantages when the relevant group is heterogeneous, so that a single approach is unlikely to fit diverse circumstances. (We return to the issue of personalization below. ${ }^{103}$ )

2. No panacea. Notwithstanding its important advantages and the frequent appeal of the menu approach, active choosing will sometimes run into legitimate objections, especially in the environmental context. The initial objection is not obscure: In the face of significant externalities, it may seem odd to ask consumers to choose for themselves. Of course some consumers may attend to those externalities and make their selections accordingly. Social norms, self-perception, and signaling may well incline them in that direction. But if a central goal is to reduce air pollution and emissions of greenhouse gases, active choosing may well be inadequate.

An independent problem is that active choosing can impose large burdens on choosers. That burden may be costly or unwelcome. Suppose that an environmental question is unfamiliar and complicated. Suppose that consumers lack information or experience. In the context of energy choices, many consumers may welcome a default, which will relieve them of the duty of having to focus on an issue that they would like to ignore. At the same time, active choosing can impose large burdens on providers. Defaults can be desirable and even important for those who provide goods or services. Without default rules, significant resources might have to be devoted to patient, tedious explanations and to going through the various options with consumers or users, who might not welcome the exercise.

A final point is that active choosing can increase errors. The goal of active choosing is to make people better off. But if the area is unfamiliar, highly technical, and confusing, active choosing might have the opposite effect. If consumers are required to answer a set of technical questions about energy options, and if the choice architects know what they are doing, then people will probably enjoy better outcomes with defaults. Perhaps it would be best to rely on experiments or pilot studies that elicit choices from informed people, and then to use those choices to build defaults. But if choice architects have technical expertise and are trustworthy, there is a question whether this exercise would be worthwhile.

3. A very simple conclusion. The conclusion is that if choice architects have reason to be confident about the preferred default, they should select it, at least if it is feasible to do

${ }^{103}$ See infra. 
so. If the assessment is difficult, and if their judgment is highly tentative, they should rely on active choosing, at least if the externalities are not large.

\section{B. Influenced Active Choosing}

It is possible to imagine a variety of variations on active choosing. For example, active choosing might be "enhanced," or influenced, in the sense that one of the choices might be highlighted or favored, perhaps through the use of behaviorally informed strategies. ${ }^{104}$ If choice architects intend to avoid a default rule but nonetheless want to promote selection of a green option, they might list it first, or use bold or a large font, or adopt verbal descriptions that make it especially salient or appealing.

Consider a relevant study in which choice was enhanced, in the sense of being influenced, by enlisting loss aversion to discourage selection of the option disfavored by the experimenters. ${ }^{105}$ The experimenters introduced several different messages in the following way:

We would like you to imagine that you are interested in protecting your health. The Center for Disease Control indicates that a flu shot significantly reduces the risk of getting or passing on the flu virus. Your employer tells you about a hypothetical program that recommends you get a flu shot this Fall and possibly save $\$ 50$ off your bi-weekly or monthly health insurance contribution cost.

In the opt-in condition, people were asked to "Place a check in the box if you will get a Flu shot this Fall." In a neutral active choice condition, people were asked to "Place a check in one box: I will get a flu shot this Fall or, I will not get a flu shot this Fall." With enhanced or influenced choice, people were asked to choose between two alternatives: "I will get a Flu Shot this Fall to reduce my risk of getting the flu and I want to save $\$ 50$ or, I will not get a Flu Shot this Fall even if it means I may increase my risk of getting the flu and I don't want to save \$50." Compared to opt-in, the active choice condition led to a significant increase in the percentage of people who would get a flu shot -- and the percentage was highest when active choice was influenced.

We could easily imagine analogues in the environmental context, for instance when a green default is not obviously right, is not feasible, or is ethically questionable. If a green default is rejected, but if there is nonetheless good reason to promote the green option, loss aversion and framing might be enlisted to encourage people to select it. The result would almost certainly be to increase the number of people who choose that option. The general point is that active choosing can be more or less neutral with respect to green and gray options. As the choice architect becomes decreasingly neutral, active choosing starts to look closer to a default rule.

\section{Green Personalization? (Gray Personalization?)}

\footnotetext{
${ }^{104}$ See Punam Anand Keller et al., Enhanced Active Choice: A New Method to Motivate Behavior Change, 21 J. CONSUMER PSYCHOL. 376 (2011).

${ }^{105} \mathrm{Id}$.
} 
Thus far we have been speaking as if default rules apply to all of a relevant population ("mass defaults"), but some default rules are highly personalized. Personalized defaults draw on available information about which approach is sought by, or best suits, different groups of people, and potentially each individual person, in the relevant population. In the context of travel preferences, personalized defaults are increasingly familiar. A website might know where you like to sit, which airline you prefer, and how you like to pay. A bit like a close friend, a sibling, a partner, or a spouse, it defaults you into your preferred choices while allowing you to opt out. ${ }^{106}$

In the fullness of time, the same will be possible for a wide range of consumer products. Personalization might also be possible for choices that affect the environment. Choice architects might know, for example, that certain people like single-sided or double-sided printing, or are highly likely to be drawn to green or gray energy. The best evidence would be their past choices. If consumers have made green choices in the past, we might expect that they will do so in the future, and set defaults accordingly (while of course allowing opt out) ${ }^{107}$ Lacking that evidence, choice architects might know relevant demographic or other factors, suggesting that certain people or certain communities would or would not prefer green energy. If the goal is to reflect the likely choices of consumers, personalized default rules have significant advantages. But a potential problem remains: If there are significant externalities, the interests of choosers are not the only consideration, and the default rule should be chosen only after consideration of the full set of social effects. ${ }^{108}$

\section{A Framework for Choice Architects}

We have now identified a large number of options that choice architects might consider, and it will be useful to offer a brief sketch of a general framework, based on the discussion thus far, that might be used to select among the various options. The framework is designed for situations in which environmental factors are particularly relevant, but it might well be adapted more generally.

Choice architects might be in a position to choose among a continuum of nine stylized possibilities, marked from most green to most gray: (1) green mandate or ban; (2) green default with costly opt-out; (3) green default with costless opt-out; (4) active choosing with pro-green presentation of some kind; (5) active choosing with neutral presentation; (6) active choosing with pro-gray presentation of some kind; (7) gray default with costless opt-out; (8) gray default with costly opt-out; (9) gray mandate or ban. (Of course the ideas of "green" and "gray" are not unitary, and include possibilities that can themselves be arrayed along a continuum; the same is true of "costless" and

\footnotetext{
${ }^{106}$ See the discussion of "sensory defaults" and "predictive defaults" in Eric Johnson et al., supra note, at 491.

${ }^{107}$ See Sunstein, supra note, for discussion of personalized defaults in general, including the risk to personal privacy.

${ }^{108}$ Recall that a mandate, and not mere default rule, might be justified in the face of significant externalities.
} 
"costly" opt-out.) As we have seen, an appealing general framework is rooted in some kind of cost-benefit analysis (bracketing some of the debates over that contested idea ${ }^{109}$ ). Enforcement costs are of course part of that analysis, and choice architects should also consider the independent value of freedom of choice and the costs associated with overriding it ("autonomy costs"). ${ }^{110}$

An implication of the discussion thus far is that without a market failure of some sort, the argument for any kind of mandate or ban is weak. ${ }^{111}$ If the interests of choosers are all that is at stake, their own freedom should generally be preserved, so long as their choices are properly informed. On the choice architecture continuum, this conclusion rules out the more aggressively regulatory poles (1) and (9). The choice among the remaining options depends on an analysis of which approach is in the interest of choosers and the confidence that choice architects have about their conclusion on that count. If they have reason for real confidence that a green or gray default is best (from the standpoint of all or most informed choosers), they should choose that default (perhaps with personalization, if feasible). In such cases, the effort costs and error costs associated with active choosing may well be too high to justify that approach (subject to the qualifications, noted above, about the limited domain of defaults).

If choice architects lack such confidence, the set of reasonable options narrows to points (2) through (6) (the middle of the continuum). Active choosing with neutral presentation is appealing if choice architects do not know which approach is best, perhaps because they lack information, perhaps because the relevant population is heterogeneous. If choice architects know enough to favor one or another approach, but not enough to set a default, they might use active choosing with some kind of non-neutral presentation, meant to incline choosers in a particular direction.

Of course the analysis must be different in the face of externalities. If the decisions of choosers would impose significant costs on others, the argument for a mandate or a ban is significantly strengthened and may be convincing (with an acknowledgement that mandates and bans come in different forms, and some approaches are less costly and more choice-preserving than others ${ }^{112}$ ). Sometimes, however, mandates or bans are not feasible, and sometimes there is a reasonable dispute about whether they are justified. In such cases, there is a serious argument for a green default, even if it is not necessarily in the interest of choosers themselves. The strength of that argument depends on whether the externalities appear large and whether choosers would be significantly helped, or instead hurt, by a green default. A form of cost-benefit analysis is indispensable here. In the face of externalities, the "less green" points on the continuum lack much appeal, and

\footnotetext{
${ }^{109}$ For helpful discussion, see Matthew Adler, Well-Being and Distribution (2011); Matthew Adler and Eric Posner, New Foundations of Cost-Benefit Analysis (2008).

${ }^{110}$ See Cass R. Sunstein, Nanny Statecraft (forthcoming 2014); Bjorn Bartling et al., The Intrinsic Value of Decision Rights (2013), available at http://papers.ssrn.com/sol3/papers.cfm?abstract_id=2255992

${ }^{111}$ A behavioral market failure might justify a mandate or ban, but even in the face of such a failure, freedom-preserving responses are usually best. See Sunstein, supra note 94.

${ }^{112}$ See A. Denny Ellerman et al., Markets for Clean Air (2005)
} 
the only potential argument in their favor is that the externalities are modest and that choosers would be far better off with a grayer approach.

Distributional questions must also be considered. If a mandate would have serious adverse effects on those at the bottom of the economic ladder, those effects should be taken into account. ${ }^{113}$ As we have suggested, a personalized approach, exempting those who cannot easily bear the relevant costs, might well make sense. And in the face of a well-justified mandate or ban, perhaps steps could be taken to give economic help to those who need it.

\section{Conclusion}

Economic incentives are of course exceedingly important, but with respect to the environment, consumer choices are greatly affected by a wide range of influences, including social norms and the applicable default rule. When the automatic choice is not green, it might well take a great deal of work for people to identify and to select environmentally preferable approaches. Even when that work seems relatively easy, people may not do it (in part because of inertia and procrastination), and the results may include both economic and environmental harm.

Green defaults are easiest to justify when they will simultaneously save money and protect the environment; consider motion detectors, automatic "off" defaults, and doublesided printing defaults. In some cases, however, green defaults will be costly to consumers. For example, smart grids and smart meters have potentially large benefits, but they may also impose costs as a result of traceability and reduced data privacy. No one should favor a situation in which choice architects select defaults that cost consumers a great deal (perhaps in terms of money, perhaps in terms of privacy) and deliver only modest environmental benefits. Some of the hard cases arise when the green default would cost consumers a nontrivial amount but also appear to produce significant environmental benefits.

In such cases, choice architects have two reasonable options. The first is to call for active choosing (and to inform consumers in the process). The second is to assess costs and benefits and to select the default rule on the basis of the assessment. The choice between the reasonable options depends on whether choice architects have justified confidence in the assessment of costs and benefits. If they do, and if the assessment demonstrates that the green default is unambiguously superior, they should choose it. The argument for active choosing becomes stronger as that assessment becomes more ambiguous, speculative, and tentative.

However the hardest cases are resolved, the basic point is clear. In important contexts, outcomes are harmful to the environment and also to the economy, not because consumers have actively chosen to impose those harms, but because of the relevant

${ }^{113}$ See John Graham, Saving Lives through Administrative Law and Economics, 157 U Pa L Rev 395 (2008). 
choice architecture. In some cases, the architecture cannot be changed by individual consumers, and some kind of collective action, whether private or public, is necessary to supply a corrective. In other cases, the architecture is effectively a default rule, as in the cases of double-sided printing and gray energy sources. In such cases, active choosing may well have significant advantages.

At least some of the time, however, the best approach is automatically green. Wellchosen default rules, attentive to the full set of costs and benefits, are likely to emerge as a significant contributor to efforts to protect human health and the environment potentially more effective, in many cases, than either information and education or substantial economic incentives. 